\title{
Tourism as a factor of long-run economic growth: An empirical analysis for Chile
}

\author{
Juan Gabriel Brida ${ }^{1 *}$ and Wiston Adrián Risso ${ }^{2}$ \\ Submitted: 19/03/2009 Accepted: 06/06/2009
}

\begin{abstract}
1 Competence Centre in Tourism Management and Tourism Economics (TOMTE), School of Economics and Management - Free University of Bolzano, Italy; tel.: +39 0471 013492, fax: +39 0471013 009, e-mail: JuanGabriel.Brida@unibz.it

2 School of Economics and Management - Free University of Bolzano, Italy; tel.: +39 0471013492 , fax: +390471 013 009, e-mail:Wiston.Risso@unibz.it and Department of Economics - University of Siena, Italy; tel.: +39 0577 235058, fax: +39 0577 232661, e-mail: risso@unisi.it

* Corresponding author
\end{abstract}

\begin{abstract}
This paper empirically investigates the impact of tourism on the long-run economic growth of Chile by using the Johansen analysis to obtain a co-integrated vector among the relevant variables and the Granger Causality test to investigate causality. We use annual data from 1988 to 2008 of the GDP of Chile, the tourism expenditure and the real exchange rate. The Johansen analysis shows that both elasticities of the co-integrated vector are positive and the Granger test shows that causality goes unidirectionally from tourism and real exchange rate to real GDP. Impulse response analysis shows that a positive shock in the tourism expenditure and the real exchange rate first produces negative effects and then a continuous and sustained positive impact.
\end{abstract}

(C) 2009 International University College. All rights reserved

Keywords: economic growth; tourism expenditure; Johansen cointegration; Granger causality

Citation: Brida, J. G., W. A. Risso (2009) Tourism as a factor of long-run economic growth: An empirical analysis for Chile. European Journal of Tourism Research 2(2), pp. 178-185

\section{Introduction}

The beliefs that exports can cause long-run economic growth are known in the literature as the Export Led Growth Hypothesis (ELGH). There are many studies investigating empirically the ELGH, but overall conclusions are mixed and contradictory. In many countries, foreign currency receipts from tourism exceeded receipts from all other sectors. Some authors (Shan and Wilson (2001) and references therein) have recently proposed the tourism-led growth hypothesis
(TLGH) that sustains that international tourism is a strategic factor for long-run economic growth. As in the ELGH, international tourism is recognized to have a positive effect on the increase of long-run economic growth through different channels. First, tourism is a significant foreign exchange earner contributing to capital goods that can be used in the production process. Second, tourism has an important role in stimulating investments in a new infrastructure and competition. Third, tourism stimulates other 
economic industries by direct, indirect and induced effects. Fourth, tourism contributes to generate employment and to increase income. Five, tourism causes positive economies to scale. Finally, tourism is an important diffusion factor of technical knowledge, stimulation of research and development and accumulation of human capital.

Most research in tourism has been focused on demand modeling (see Song et al. (2000), $\mathrm{Li}$ et al. (2005), and Song and Li (2008)). Research in the TLGH is very recent and results of the impact of international tourism to the long run economic growth are still inconclusive. Balaguer and Cantavella (2002) examine the role of tourism in the long run economic growth of Spain, confirming the validity of the TLGH in this case. CortésJiménez and Pulina (2006) investigated the TLGH for Spain and Italy by using cointegration techniques and multivariate Granger causality test. They show that exports cause growth in the long run for both countries, whilst only for Spain tourism appears as a factor which influences long-run economic growth. Dritsakis (2004) investigated the impact of tourism on the long-term economic growth of Greece by using causality analysis and found evidence of bidirectional causality between international tourism and economic growth in the case of this country. Gunduz and Hatemi-J (2005) empirically confirmed the TLGH in the case of Turkey using the leveraged bootstrap causality tests. They found unidirectional causality running from international tourist arrivals to economic growth of Turkey. Ongan and Demiroz (2005) also examined the impact of tourism on the long-term economic growth of Turkey by using cointegration and Granger causality testing. They found bidirectional causality between tourism and economic growth of Turkey in both the short and the long-run. By the contrary, Katircioglu (2009) does not find any cointegration between international tourism and long-term economic growth in Turkey, rejecting the TLGH for the Turkish economy. Using cointegration and causality tests, Durbarry, R. (2004), Louca (2006), Noriko and Motosugu (2007), and Gani (1998) present support for the validity of TLGH for some small islands including Mauritius, Cyprus, Amami islands in Japan, South Pacific islands. Oh (2005) investigates the TLGH for Korea, showing that there is no long-run equilibrium relation between the variables and a one-way causal relationship of economic-driven tourism growth. Kim et al. (2006) examines the TLGH for Taiwan supporting a long-run equilibrium relationship and a bi-directional causality between the two factors. In other words, in Taiwan, tourism and economic development reinforce each other. Similarly, Proença and Soukiazis (2005) provides evidence of the positive impact of tourism (through the accommodation capacity) on the growth in per-capita income among the Portuguese regions, Shan and Wilson (2001) investigate the causality relationships between international tourism and international trade flows using the case of China. They show a two-way Granger causality between the two variables. Brida et al. (2008) investigate the case of Mexico, showing the existence of one co-integrated vector among real GDP, tourism expenditure and real exchange rate where the corresponding elasticities are positive. Nowak et al. (2007) investigates the link between tourism exports and economic growth in the Spanish context using a multivariate Granger test based on a VECM. They show that the TLGH cannot be rejected. Eugenio-Martin et al. (2004) analyze the relationship between tourism and economic growth for Latin American countries since 1985 until 1998 using a panel data approach and the Arellano-Bond estimator for dynamic panels. They show that tourism is adequate for the economic growth of medium or low-income countries, though not necessarily for developed countries. Lee and Chang (2008) apply the new heterogeneous panel cointegration technique to investigate the TLGH for OECD and non OECD countries. They show that tourism has a greater impact on GDP in non OECD countries than in OECD countries. Their panel causality test shows unidirectional causality relationships from tourism development to economic growth in OECD countries, bidirectional relationships in non OECD countries, but only weak relationships in Asia. 
The purpose of this study is to investigate the TLGH for Chile. In a recent study, Siliverstovs and Herzer (2006) support the ELGH for Chile with the unidirectional Granger causality running from the manufactured and primary exports to the output but not vice versa. Tourism is not considered in that paper as part of exports, nevertheless the sector has experienced an impressive growth during the recent past. This is the first motivation for our study: to study if tourism as manufactured and primary exports exerts a relevant impact on the long-run economic growth of Chile. During the last three decades the country experienced a high performance in economic growth and this growth was followed by a significant growth of tourism. Chile's natural beauties as the Atacama desert, the Eastern island and the mountains and glaciers of Patagonia attract millions of international tourists each year. The number of international tourists increased from 1.412 million in 2002 to 2.253 million in 2006 with an average rate of growth of $12 \%$ during this period. Chile is a country relatively isolated from major global markets in North America and Europe due to its geographical location. This determines that most of the international tourists arriving in the country are from Argentina, but the participation of Argentinean tourists is constantly decreasing in the last decade passing from $50 \%$ of the total tourists in 2000 to $30 \%$ in 2006 . The decline of the participation of the Argentinean tourists was followed by an increase in the participation of North Americans and Europeans (changing from $10 \%$ and $13 \%$ in 2000 to $12.5 \%$ and $17 \%$ in 2006 respectively). Also the rest of the Latin-American countries increased the fraction of total international tourists from $24 \%$ in 2000 to $34 \%$ in 2006 . Although the tourism industry has grown significantly in this country, tourism researchers have not paid much attention to the empirical assessment of contributions of the tourism sector to this country.

The objective of this study is to investigate the TLGH for Chile. Subsequently, the paper aims to answer the following questions. First, is there a long-run equilibrium relationship between tourism and economic growth in Chile? Second, if a stable long-run relationship exists, what is the direction of this causal relationship? We empirically investigate the long-run co-movements and the causal relationships between tourism (measured as the tourist expenditure), economic growth (measured by real GDP) and the real exchange rate. The hypotheses are tested empirically by using the cointegration test by Johansen (1988), Johansen and Joselius (1990) and Johansen (1995). In addition, the Granger Causality test (see Granger (1988)) is applied.

The study contributes to the existing literature in the following ways. First, it finds evidence of causality going unidirectionally from tourism and real exchange rate to real GDP. To the best of the present authors knowledge, this is the first study examining this hypothesis for Chile and applying the Toda and Yamamoto (1995) procedure to test it. Second, it shows that the elasticities of the co-integrated vector obtained from the Johansen methodology are positive. In particular, it also shows that the elasticity of per capita GDP with respect to tourism for Chile is higher than the elasticities obtained for other Latin-American countries.

The paper is organized as follows. In the next section we introduce data and methodology used in this study and some results from the empirical analysis are discussed. The results of this paper and previous empirical studies are compared in Section 3. Finally, Section 4 presents the concluding discussion and further comments.

\section{Data, model and results}

It is difficult to find long time series of tourism for Chile. We were not able to obtain monthly or quarterly date, that would have permitted to apply seasonal co-intregration and taking into account possible differences in winter and summer. However, we found annual data from 1988 to 2008 of tourism for Chile. Data of real GDP and real exchange rate $(R E R)$ are obtained from the Central Bank of Chile. Tourism expenditure (TourExp) is measured by the Real Travel and Tourism Consumption 
provided by the World Travel \& Tourism Council. We first proceeded to identify the order of integration of the series by applying the ADF and the KPSS unit root tests, detecting that the series were integrated of order 1. (see Table 1).

The second step is to apply the cointegration test proposed by Johansen (1988) to detect all the possible co-integrating relationships. Banerjee et al. (1993) highlight that to find a cointegration is equivalent to obtain a statistical equilibrium between variables tending to grow over time. The discrepancy of this equilibrium can be modeled by a Vector Error Correction (VEC) model:

$$
\Delta Y_{t}=\mu+\Pi Y_{t-1}+\sum_{i=1}^{i=k-1} \Gamma_{i} \Delta Y_{t-i}+\varepsilon_{t}
$$

where $Y=(G D P$, TourExp, RER) is a vector containing the variables, $\mu$ is a vector of constant terms and $\varepsilon_{t}$ is a normally distributed vector of errors, with a zero mean and a positive definite covariance matrix. The matrix $\Pi$ conveys information about the long-run relationship between the $Y$ variables. The rank of $\Pi$ is the number of linearly independent and stationary linear combinations of the variables. The VEC shows how the variables come back to the equilibrium after suffering a shock. In order to obtain an optimal VEC, we select a model with length one. To determine the number of cointegrating equations, the Johansen maximum likelihood method provides both trace and maximum eigenvalue statistics. Table 2 resumes both tests and shows the existence of one co-integrating vector.

We find that TourExp and RER are weakly exogenous $\left(C h i^{2}(1)=3.09, p\right.$-value $=0.08$ and $\operatorname{Ch}^{2}(1)=0.37, p$-value $=0.54$ respectively). The joint test of exogeneity for TourExp and RER indicates a statistic of 3.369 and a $p$-value of 0.185 , indicating that exogeneity cannot be rejected at $5 \%$ level. Then we can draw inference and equation (2) shows the long-run equilibrium after testing weak exogeneity of tourism expenditure and RER ( $t$-statistics appear in []): $(\text { real GDP })_{t}=15.189+0.817\left(\right.$ TourExp $_{t}+0.346(R E R)_{t}$ (2)

$$
\text { [-20.34] [-12.59] }
$$

Note that the elasticity of real GDP with respect to tourism expenditure is 0.817 . Based on the previous results, we proceed with testing for dynamic Granger causality in the VAR model by using the Toda and Yamamoto (1995) methodology. This methodology is a procedure that generalizes Granger (1988): when the variables are integrated, they propose to estimate a VAR model with $(k+d \max )$ lags, where $k$ is the standard optimal number of lags and dmax is the maximal order of integration that we suspect might occur in the process. Once the VAR is estimated, we test Granger causality by using only the first $k$ lags. The hypothesis is tested using the Wald method. However, Toda and Yamamoto (1995) assert that Wald and LR tests are asymptotically equivalent in the present situation. Table 3 shows the results for all the variables.

Apparently, the null hypothesis that the tourism expenditure (or RER) does not Granger cause real GDP is decisively rejected and the null hypothesis that the real GDP does not Granger cause tourism expenditure (resp. RER) is accepted. Thus, there exists the unidirectional Granger causality from the tourism expenditure and the $R E R$ to the real GDP. This is interpreted as empirical evidence of the TLGH. In addition, we study the impulse response functions. Figure 1 shows that after a shock in tourism expenditure, the initial response of real GDP is to fall being negative and then it presents a sustained positive response. Moreover, a shock in $R E R$ first produces a negative response but then a positive reaction on the real GDP.

A positive shock in the tourism expenditure positively affects the long-run real GDP. A positive shock in $R E R$, (real devaluation) has first a negative effect for 3 years and then a high positive effect; this is the discussed $\mathrm{J}$ curve (see Magee (1973) and BahmaniOskooee (1985)). 


\section{Comparing results}

The results of this study and previous empirical papers investigating the TLGH for other Latin American countries are compared in Table 4. The papers included in the table have been selected for the econometric approach. The table 4 shows the direction of causality and the elasticity of per capita GDP with respect to tourism. Notice that the elasticity in Chile is the largest among the sample of Latin-American countries. What strikes is the notable impact of tourism on the economic growth in the last two decades.

Notice also that the hypothesis of unidirectional causality from tourism to economic growth is also accepted in the rest of the Latin-American countries, highlighting the importance of the sector as an engine of economic growth.

\section{Table 1: Unit Root Test: Levels and First Differences}

\begin{tabular}{|l|r|r|r|r|r|r|}
\hline \multicolumn{9}{|c|}{ Levels } \\
\hline \multicolumn{1}{|c|}{ Variable } & \multicolumn{2}{|c|}{ real GDP } & \multicolumn{2}{|c|}{ TourExp } & \multicolumn{2}{c|}{ RER } \\
\hline Unit Root Test & ADF & KPSS & ADF & KPSS & ADF & KPSS \\
Trend, Constant & -3.10 & 0.15 & -1.48 & $0.19^{*}$ & -2.94 & 0.13 \\
Constant & -2.95 & 0.63 & -2.88 & $0.62^{*}$ & $-3.13^{*}$ & 0.21 \\
Without Trend, Const. & 2.46 & & 3.10 & & -1.04 & \\
\hline
\end{tabular}

${ }^{*}$ Null Hypothesis Rejection at $5 \%$

\begin{tabular}{|l|r|r|r|r|r|r|}
\hline \multicolumn{7}{|c|}{ First Difference } \\
\hline \multicolumn{1}{|c|}{ Variable } & \multicolumn{1}{|c|}{$\boldsymbol{\Delta}$ (real GDP) } & \multicolumn{1}{c|}{$\boldsymbol{\Delta}$ (TourExp) } & \multicolumn{2}{|c|}{$\boldsymbol{\Delta ( R E R )}$} \\
\hline Unit Root Test & ADF & KPSS & ADF & KPSS & ADF & KPSS \\
Trend, Constant & -3.41 & 0.13 & $-4.60^{*}$ & $0.50^{*}$ & -2.78 & 0.10 \\
Constant & $-3.12^{*}$ & 0.43 & $-3.68^{*}$ & 0.39 & -2.90 & 0.15 \\
Without Trend, Const. & -1.67 & & -1.45 & & $-2.87^{*}$ & \\
\hline
\end{tabular}

${ }^{*}$ Null Hypothesis Rejection at $5 \%$

Table 2: Cointegration Rank Test (Trace and Maximum Eigenvalue)

\begin{tabular}{|ll|}
\hline Trend assumption: & No deterministic trend \\
Series: & real GDP, TourExp and RER \\
\hline
\end{tabular}

Trace test

\begin{tabular}{|l|r|r|r|r|}
\hline Hypothesized No. of CE & Eigenvalue & Trace Stat. & Critical Value & \multicolumn{1}{c|}{ Prob. } \\
\hline None $^{\star}$ & 0.863 & 53.505 & 35.193 & 0.0002 \\
At most 1 & 0.432 & 15.762 & 20.262 & 0.1858 \\
At most 2 & 0.232 & 5.024 & 9.164 & 0.2808 \\
\hline
\end{tabular}

Maximum Eigenvalue

\begin{tabular}{|l|r|r|r|r|}
\hline Hypothesized No. of CE & Eigenvalue & Max-Eigen Statistic & Critical Value & Prob. \\
\hline None* & 0.863 & 37.743 & 22.299 & 0.0002 \\
At most 1 & 0.432 & 10.738 & 15.892 & 0.2718 \\
At most 2 & 0.232 & 5.024 & 9.164 & 0.2808 \\
\hline
\end{tabular}

Trace and Max.Eigen. test indicates 1 cointegrating eqn(s) at the 0.05 level

* Denotes rejection of the hypothesis at the 0.05 level

Table 3: Granger Causality Test (by Toda \& Yamamoto)

\begin{tabular}{|l|r|r|}
\hline \multicolumn{1}{|c|}{ Null Hypothesis } & Wald-statistic & P-value \\
\hline TourExp does not Granger Cause real GDP & 9.498 & $0.009^{*}$ \\
real GDP does not Granger Cause TourExp & 5.586 & 0.061 \\
RER does not Granger Cause real GDP & 6.398 & $0.041^{*}$ \\
real GDP does not Granger Cause RER & 0.700 & 0.704 \\
RER does not Granger Cause TourExp & 1.587 & 0.452 \\
TourExp does not Granger Cause RER & 1.201 & 0.548 \\
\hline
\end{tabular}

* Indicates rejection of the null hypothesis at $5 \%$. We used a VAR with $\mathrm{k}+d \max =2+1$. $\mathrm{P}$-values correspond to the Chi-square distribution with 2 degree of freedom. 
Response of GDP to Tourism Expenditure

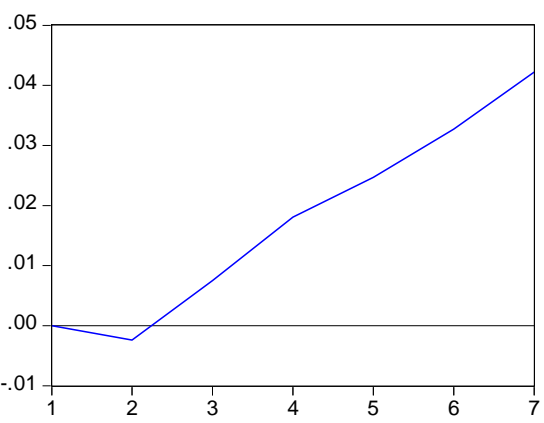

Response of GDP to Real Exchange Rate

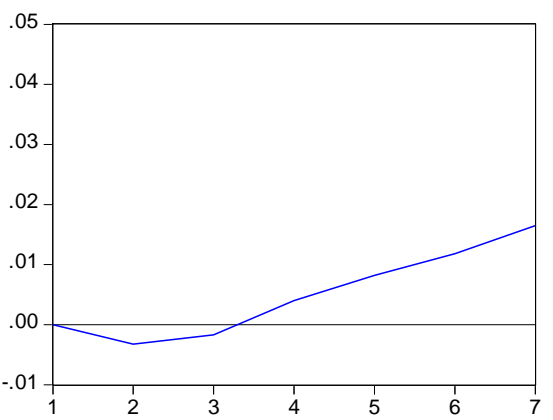

Figure 1: Impulse Response Functions of GDP

Table 4: Previous empirical results for the TLGH in Latin American countries

\begin{tabular}{|l|l|l|c|c|l|}
\hline \multicolumn{1}{|c|}{ Country } & \multicolumn{1}{|c|}{ Period } & Periodicity & Causality & $\boldsymbol{E}$ & \multicolumn{1}{c|}{ Paper } \\
\hline Mexico & $1980-2007$ & quarterly & $A$ & 0.69 & Brida et al. (2008) \\
\hline Colombia & $1987-2007$ & quarterly & $A$ & 0.51 & Brida et al. (2009a) \\
\hline $\begin{array}{l}\text { High income Latin American } \\
\text { Countries }\end{array}$ & $1985-1998$ & annual & $N$ & - & Eugenio-Martin et al. (2004) \\
\hline $\begin{array}{l}\text { Low and medium income Latin } \\
\text { American Countries }\end{array}$ & $1985-1998$ & annual & $A$ & - & Eugenio-Martin et al. (2004) \\
\hline MERCOSUR and Chile & $1990-2000$ & annual & - & 0.74 & Gardella and Aguayo (2002) \\
\hline Uruguay & $1987-2006$ & quarterly & $A$ & 0.42 & Brida et al. (2009b) \\
\hline $\begin{array}{l}\text { Chile } \\
\text { Note that E denotes the elasticity of per capita GDP with respect to tourism, } A \text { denotes unidirectional causality from } \\
\text { tourism to economic growth, B denotes unidirectional causality from economic growth to tourism, C denotes bidirectional } \\
\text { causality between tourism and economic growth and N denotes no evidence for causality. }\end{array}$ \\
\hline
\end{tabular}

In fact, Eugenio-Martin et al (2004) found that the growth in tourists per capita experienced a significant economic growth during the period between 1985 and 1998. They observed that tourism growth was associated with economic growth only in low and medium income countries, but not in high income countries. The authors assert that tourism development might contribute to the economic growth of the country provided it is below a GDP per capita threshold, while such a role is unclear if the country is already developed.

\section{Conclusion}

We studied the impact of the tourism in the economic growth of Chile in the context of the TLGH. We find that the international tourist's expenditure positively impacts the Chilean economic growth. The elasticity of real GDP to tourism expenditure is 0.81 , this is the largest elasticity compared with other LatinAmerican countries. The real exchange rate produces also a positive effect with elasticity of 0.35. To test the TLGH we applied the Granger-causality test using the more robust methodology suggested by Toda and Yamamoto (1995), showing that the tourism expenditure unidirectionally affects economic growth. Then the TLGH is supported for the Chilean economy, suggesting that tourism is an important determinant of overall long-run economic growth. A policy implication which may be drawn from this study is that Chile can improve its economic growth performance by strategically harnessing the contribution of the tourism industry and improving their governance performance. Since tourism is an important engine of local development, it is necessary to increase domestic tourism in order to have more decentralization of local development caused by such activity. The study justifies the necessity of continuing with the successful public intervention in the tourism activity with investments in tourism infrastructures, improving transportation and telecommunication systems, applying subsidies and given 
funds and incentives to tourism related activities to develop alternative forms of tourism, promoting tourism in foreign countries and monitoring continuously the tourism activity.

\section{Acknowledgements}

Our research was supported by the Competence Centre in Tourism Management and Tourism Economics (TOMTE) of the Free University of Bolzano project: "Tourism, growth, development and sustainability. The case of the South Tyrolean region". We would also like to thank the helpful comments of anonymous referees. A preliminary version of this paper was presented at the conference "Advances in Tourism Economics" (ATE2009), Research Centre in Tourism, Innovation and Services (CITIS) of Universidade Lusiada de Lisboa, 23-24 April 2009.

\section{References}

Balaguer, J., M. Cantavella-Jordà (2002) Tourism as a long-run economic growth factor: the Spanish case. Applied Economics 34(7), pp. 877884

Bahmani-Oskooee, M. (1985) Devaluation and the J-curve: some evidence from LDCs. Review of Economics and Statistics, 67(3), pp. 500-504

Banerjee, A., J. Dolado, J. Galbraith, D. Hendry (1993) Co-integration, ErrorCorrection, and the Econometric Analysis of the Non-Stationary Data. Oxford University Press.

Brida, J. G., E. Carrera, W. A. Risso (2008) Tourism's Impact on Long-Run Mexican Economic Growth. Economics Bulletin, 3(7), pp. 1-10

Brida, J. G., W. A. Risso, S. Zapata Aguirre, M. J. Such, e Pereyra, J. S. (2009a) Turismo y crecimiento económico: un análisis empírico de Colombia, Estudios y Perspectivas en Turismo, 18(1), pp. 21-35

Brida, J. G., B. Lanzilotta, S. Lionetti, W. A. Risso (2009b) The tourism-led-growth hypothesis for Uruguay. Tourism Economics (forthcoming) Available at
SSRN:

http://ssrn.com/abstract=1333102

Cortez-Jimenez, I., M. Paulina (2006) A further step into the ELGH and TLGH for Spain and Italy, in Fondazione Eni Enrico Mattei Working Paper Series. Nota di Lavoro 118-2006

Dritsakis, N. (2004) Tourism as a long-run economic growth factor: an empirical investigation for Greece using causality analysis, Tourism Economics, 10(3), pp.305-316

Durbarry, R. (2004) Tourism and economic growth: The case of Mauritius. Tourism Economics, 10(3), 389-401

Eugenio-Martin, J. L., N. M. Morales, R. Scarpa (2004) Tourism and Economic Growth in Latin American Countries: A Panel Data Approach. Fondazione Eni Enrico Mattei Working Paper Series. Nota di Lavoro 26.2004

Gardella, R., E. Aguayo (2002) Impacto Economico del Turismo en el Mercosur y Chile. Estudios Economicos de Desarrollo Internacional. AEEADE. Vol. 2(1)

Granger, C. (1988) Some recent developments in a concept of causality. Journal of Econometrics, 39(1-2), pp. 199-211

Gunduz, L., A. Hatemi, (2005) Is the tourismled growth hypothesis valid for Turkey? Applied Economics Letters, 12(8), pp. 499-504

Johansen, S. (1988) Statistical Analysis of cointegration vectors. Journal of Economic Dynamics and Control, 12(4), pp. 231-254

Johansen, S., K. Juselius (1990) Maximum likelihood estimation and inference on cointegration with applications to the demand for money. Oxford Bulletin of Economics and Statistics, 52(2), pp. 169-210

Johansen, S. (1995) Likelihood-based inference in cointegrated vector autorregressive models. Oxford: Oxford University Press

Katircioglu, S. T. (2009) Revisiting the tourism-led-growth hypothesis for Turkey using the bounds test and Johansen approach for cointegration, 
Tourism Management, 30(1), pp. 1720

Kim, H. J., M. Chen, S. Jan, (2006) Tourism expansion and economic development: The case of Taiwan. Tourism Management, 27(5), pp. 925933

Lee, C. C., C. P. Chang, (2008) Tourism development and economic growth: a closer look at panels. Tourism Management, 29(1), pp. 180-192

Louca, C. (2006) Income and expenditure in the tourism industry: time series evidence from Cyprus, Tourism Economics, 12(4), pp. 603-617

Narayan, P. (2004) Economic Impact of Tourism on Fiji's Economy: Empirical Evidence from the Computable General Equilibrium Model, Tourism Economics, 10(4), pp. 419-433

Noriko, I., F. Mototsugu (2007) Impacts of tourism and fiscal expenditure to remote islands: the case of the Amami islands in Japan. Applied Economics Letters, 14(9), pp. 661666

Nowak, J. J., M. Sahli, I. Cortés-Jiménez (2007) Tourism, capital good imports and economic growth: theory and evidence for Spain. Tourism Economics, 13(4), pp. 515-536

Oh, C. (2005) The contribution of tourism development to economic growth in the Korean economy, Tourism Management, 26(1), pp. 39-44
Ongan, S., D. M. Demiroz (2005) The contribution of tourism to the long-run Turkish economic growth. CEEOL Journal of Economics, Issue 9/2005, pp. 880-894

Proença, S., E. Soukiazis (2005) Tourism as an alternative source of regional growth in Portugal: a panel data analysis at NUTS II and III levels. Portuguese Economic Journal, 6(2), pp. 89-93

Shan, J., K. Wilson (2001) Causality between trade and tourism: empirical evidence from China. Applied Economics Letters, 8(4), pp. 279-283

Siliverstovs, B., D. Herzer (2006) Export-led growth hypothesis: evidence for Chile. Applied Economic Letters, 13(5), pp. 319-324

Song, H., G. Li (2008) Tourism demand modelling and forecasting - A review of recent research. Tourism Management, 29(2), pp. 203-220

Li, G., H. Song, S. F. Witt (2005) Recent Developments in Econometric Modeling and Forecasting. Journal of Travel Research, 44(1), pp. 82-99

Song, H., S. F. Witt (2000) Tourism demand modelling and forecasting. Oxford: Pergamon

Tosun, C. (1999) An analysis of contributions international inbound tourism to the Turkish economy. Tourism Economics, 5(3), pp. 217-250 